\title{
Re-envisioning nursing education and practice in Nigeria for the 21st century
}

\author{
Clara Agbedia \\ Department of Nursing Science, Delta State University, Abraka, Nigeria \\ Email: oniovo4life@yahoo.com
}

Received 19 March 2012; revised 16 April 2012; accepted 27 April 2012

\begin{abstract}
The paper explores the current situation and future development of nursing education and practice in Nigeria and their influence on health care. As the role of the nurse continues to expand, Nigerian nurses must be skillful in effectively using evidence-based and clinically relevant information to facilitate the best possible nursing care. Major issues and challenges in this regard are discussed with some recommendations on the way forward.
\end{abstract}

Keywords: Issues; Nursing Education;

Teaching/Learning; Practice; Partnership

\section{INTRODUCTION}

The rapidly changing health care system requires nurses to possess increasing knowledge, clinical competency, greater independence, and autonomy in clinical judgment. Furthermore, sophisticated technologies and society's orientation to health and self care are rapidly causing educational needs of nurses to grow. This development is good for the profession as well as for the consumers of nursing services because better educational preparation will lead to better performance, Two key words in this paper are; preparing and re-envisioning. Preparing connotes special activities to enhance good performance while re-envisioning means that the expectations and obligation that nurses have about themselves or the society has about them is inadequate and needs to be reviewed. The reason is not farfetched as many institutions and policies are still modeled on the assumption and conditions prevalent in the 1930s. Therefore re-envisioning nursing education and practice must be established on three fundamental

Situational, re-envisioning must take cognizance of the other reforms in health care in Nigeria, attitudinally to the extent that the existing attitude towards curriculum development and the mode of delivery of care in our hospitals must be reviewed to reflect the complexities of health care delivery in Nigeria. The outcome is a change on behavior. The premise is that nursing education and practice do not take place in isolation. Nursing takes place in real life situation with political, economical and cultural realities. Thus re-envisioning is to produce competent polyvalent nurse practitioners equipped with the knowledge and skills that ensure a care that is acceptable efficient and accessible.

\section{ISSUES IN NURSING EDUCATION AND PRACTICE}

\subsection{Nursing Education}

Nursing education in Nigeria continues to struggle with its content-overload curricula that attempts simultaneously to "prepare" nurses to practice in a biomedical orientated disease care system and to educate nurses to be responsible health care professionals committed to the social changes necessary for health promotion and disease prevention. Within this setting it is pertinent to ask some questions. This include:

- Does the basic nursing education in Nigeria provide nursing students sufficient learning experience and necessary skill?

- What are the future health needs of this nation?

- How can these nurses be best prepared?

- How can school be changed to educate these practitioners?

What is needed now is dramatic reform and innovation in nursing education to create and shape the future of nursing practice. All levels of nursing education, undergraduate and graduate, must challenge long-held traditions and design evidence-based curricula that are flexible, responsive to students' needs, collaborative, and integrate current technology.

\subsection{Pattern of Nursing Education in Nigeria}

The history of nursing education in Nigeria is similar to that of United Kingdom and the United States of America [1]. Schools of Nursing were started by Regional 
Government from 1949 to produce home grown practitioners as opposed to those trained abroad. The training started as an informal, apprenticeship training and emphasized on-the-job manipulative skill acquisition, strict obedience to institutional rules and regulations of practice and ethical conduct but with minimal opportunity for creativity, accountability, independent clinical decision making or professional development [2]. As need for more trained nurses arose, state governments and missionary organizations opened Schools of Nursing. Nursing Council of Nigeria was established in 1949 to coordinate the schools of nursing and create standards for nursing education and practice. The programmes offered by the schools were either basic or post basic in nature. The programme includes; general nursing (3 years/18 months); midwifery (3 years/1 year); psychiatry nursing (3 years/1 year) respectively either as basic or post basic. The academic curricula were reviewed severally in response to the needs of the society. Certificates offered by the three year nursing diploma programmes have recently been quantified for promotion purposes and judged to be equivalent to a Higher National Diploma Certificate to fall in line with the education and civil service structures in Nigeria. Graduates of these programmes may proceed to the university as a direct entry for a four year programme to earn a Bachelor of Nursing Science degree. As at now there are few nurses who have a single quailfication, that is, only nursing, or midwifery or psychiatry nursing and so on. What usually happens is that the female nurse with general nursing certificate undergoes the midwifery preparation to obtain what is often referred to as "double qualification". After a number of years of practice, she adds other nursing qualification. This creates an unnecessary overlap and duplication of efforts in many areas. Thus it can be argued that nurses in Nigeria are over trained especially in the diplomate level. The university nursing programmes prepare nurses at different levels and competencies.

Upon completion of first degree, individual nurse may proceed for a Master's programme to obtain M.Sc. (Nursing) and later a Ph.D. (Nursing). Currently, there are about 18 Nigerian universities offering nursing programme.

\subsection{Nursing Practice}

Nursing care approaches which Nigerian nurses have used to organize their activity traditionally and until now include: case nursing, functional nursing, primary care nursing and team nursing. Of these four models of nursing care delivery, the most prevalent in most health institutions in Nigeria and the most preferred is the functional approach. This method of care does not individualize care and it robs the nurse of developing skills in planning, implementing and evaluating care given to individual patients and it lacks continuity and holistic approach to care. This has a negative impact on best practices, standards and quality of care rendered. The need for nurses to adopt other care approaches has therefore become more compelling so that the care rendered can be of quality. The situation is worsened with acute staff shortage on the wards.

Prof A.O. Ojo in his inaugural lecture at Igbinedion University, Okada recently, x-rayed nursing care challenges in Nigeria. These according to him included the fact that the educational level of these nurses affects proper understanding and utilization of the most current concepts in nursing such as nursing process, evidencebased practice, best practices, advanced nursing practice and reflective practice etc. which are designed to improve quality of care rendered by nurses globally. That nurses themselves were slow in embracing university education thereby limiting their opportunities for progress and slow down the rate of improvement of care they render. In addition, governments' cost saving practice for minimum staff for minimum work in health care delivery system endangers the health of the citizens as standards and quality are low. All these factors are negatively impacting on the quality of care rendered by nurses. In view of these challenges, re-envisioning of nursing education and practice is the panacea.

Nursing in Nigeria is yet to recognize that nursing is both a profession and a business (market) influenced by factors of supply and demand. While a lot of efforts have been put on the profession aspect, the business aspect is underutilized. Nursing care which is the basis of practice is a commodity purchased by the patient or consumer of health service. The mode of production of the marketers of the commodity (nursing education) and the means of presentation of the commodity (type of nursing care/ services) given determine the demand and subsequently the purchase [3], therefore effective marketing strategies in nursing education and practice must be developed. The reenvisioning in clinical practice must be examined within the context of;

- Less time available for patient this decreases opportunities for nurses and doctors to get to know the patient.

- Increase in acuity, and pace of care

- Shift in role of responsibility: Previously the physiccian has been viewed as the sole accountability with regards to most aspect of care now there is a universe of clinician, nursing inclusive who under some circumstances assumes some responsibilities for care.

- Mandate to ensure safety: The continued emergence of new technology have resulted in a new emphasis on safety, of both patient and staff. 


\section{THE WORKFORCE DEMOGRAPHY}

Nursing, like other practice disciplines, is complex, meaning that they must attend to changing relevance as well as changes in the patient's responses and nature of his clinical condition over time. In discussing re-envisioning Nursing Education and Practice it is pertinent to look at the demography of nursing workforce. Demographic trends and low recruitment during structural adjustment program SAP in the 1990s in Nigeria have produced a nursing workforce that is skewed toward older workers than the general workforce. Large numbers of nurses are retiring; too few people are entering the nursing profession to replace those retirees. In their study of workers in Europe who are at several different life and career stages [4], found that those born in the same general time span share key life experiences, including historical events, public heroes, entertainment and pastimes, and early work experiences. It was also found out that knowledge and skills increases as people age, but basic characteristics, including the behavioral values and norms established in their formative years, persist.

The current nursing workforce is assumed to include representatives of four generations

- The Veterans

- The Baby Boomers

- Generation X

- The Generation Y

In translating this grouping to the existing nursing workforce in Nigeria the reason for the existing interpersonal conflict is very glaring. Older nurses considered younger nurses to be lacking in commitment, overly mobile, and arrogant. Younger nurses argued that their older colleagues misconstrued a preference for self-reliance as arrogance. The premise here is that to recruit and retain appropriately qualified staff in a competitive job market, it is imperative that nurse managers must be knowledgeable about the characteristics and preferences of employees who are at different stages of their careers. Nurse managers must utilize generational strengths. For example, Baby Boomers in supervising Generation X must employ strategies to improve interpersonal skills, provide individual attention, appreciate diversity, use humor and empathy, and treat subordinates as they would expect to be treated.

\section{THE SHORTAGE OF NURSES}

Any discussion on reform in the nursing must consider the supply and the demand for nurses. Nursing shortage refers to the inadequate number of nurses to care for patients at some professionally determined level. The shortage of nurses is well documented in nursing literature. The expanded range of setting in which nurse practice, the increasing acuity of client and the complexity of care required, the difficulty in attracting and retaining nurses, high technology, issues associated with professional nursing practice such as autonomy, job dissatisfaction, have been attributed to this staff shortage. These factors have created the need for more RNs. The use of retired nurses in the Midwives Service Scheme in Nigeria is a welcome idea; this will go a long way in reducing maternal and infant mortality.

Shortage of nurse educators within the university systems calls for concern. The quantity and quality of staff must be adequate for the number of established departments of nursing. There is usually a teacher/student ratio of 1:10 for effective learning. This has to be adhered to in order to produce competent nurses to function in all areas of nursing. Retired but productive staff can be encouraged to serve as adjunct lecturer. Attention need to be directed at creating flexible working hours as seen in UK and USA to allow return to practice, make hospital better place to work by improving overall working conditions, offering competitive salary that take cognizance of high degrees in nursing and demonstrating the value of nursing to patients. These changes will be significant in re-envisioning nursing for the 21st century.

\section{WAY FORWARD}

\subsection{Strategy 1-Partnership to Design Innovative Educational Systems}

Dramatic reform and innovation in nursing education is needed to create and sharpen the future of nursing practice. Nurse educators, students, consumers and nursing service personnel must work in partnership to design innovative educational systems that meet the needs of the health care delivery system now and in the future .For too long nurse educators and nursing service personnel, although cordial and respectful of each other, have not been fully engaged in collaborating to prepare a workforce that can practice effectively in new healthcare environments.

This current challenge demands innovative ideas, creative thinking and action, aimed at bridging the ever widening gap between theory and practice. Nurse educators need to be conversant with current practice in the clinical areas so that they can develop their research areas as well as develop theoretical basis for practice. In such a system, the very nature of "fundamental skills" and customary approaches to planning care are being challenged. Therefore, nursing service personnel must work with lecturers, and students to design innovative nursing systems that meet the needs of the health care delivery system for the 21st century.

The conventional single pedagogy in nursing education (outcome-based or competency based education is limited as shown in studies by [5] and [6]. Multiple 
pedagogies are needed that is philosophical and reflective of modern discourse. The essence is the development of signature pedagogies that is distinctively nursing reflecting the special needs and complexity of nursing education and practice. The new pedagogies must be research based, responsive to the rapidly changing care system, reflective of new partnership between and among student, teachers and the clinical nurse.

\subsection{Strategy 2-Research Priority}

Promoting research utilization through formation of Nursing Research/Committee is a potent way to promote evidence-based nursing. The Nursing and Midwifery and Council of Nigeria in collaboration with other stake holders in nursing must commission priority researches on the following:

- The bio-psychosocial aspects of nursing care of children and adults with HIV infection and their caregivers.

- Quality of nursing care across the care continuum.

- Nursing care of women at risk for bearing low birth weight infants

- Development of instrument to evaluate the effectiveness of nursing care delivery systems;

- Development of instruments for measuring symptoms such as pain, sleeplessness, fatigue, and nausea is also part of this priority.

\subsection{Strategy 3-Making Knowledge of Research a Key Criterion in the Appointment of Ward Sister}

A major influence on whether research findings are utilized or not must be the incentive offered to nurses to make the effort to become research minded. The writer contends that nursing profession may be giving only up service support to the value of research in nursing, if it is not actively creating opportunities for clinical nurses to become involved in further education and research nor offering positive recognition for nurses who are research literate and implementing findings. Perhaps, a positive move in this direction is to make knowledge of relevant research a key criterion in the appointment of ward sister or in the annual appraisal of nurse managers. In addition health service must support and provide a receptive clinical environment that is amenable to change, by creating a career structure, which formally recognizes the role of research and its relevance.

\subsection{Strategy 4-Mentoring}

Mentoring has been described as an interactive process of learning in which the reward is twofold: reaching ones goal and professionally growing together [7]. Both men- tor and protégé gain in ideals, collegial support and achievement of their mutual objectives. Thus, it can be argued that mentoring is a veritable means of bridging the gap between the older and the younger generation or even between peers and subordinate in any relationship. Many nurses currently in service have undergone some form of mentoring in their roles as colleagues, mothers, wives and heads of units. We had the opportunity to rely on senior colleagues for advice, contact, and learning of skills. What happened to all that, suddenly mentoring has become endangered species?

Benefits of Mentoring in Nursing include:

- The exchange of ideas, feedback, support, friendship, advice and information

- The protégé may enjoy career development.

- Increase in the female protégé's self esteem.

- Save cost of training and development

- Banishes stereotypes

\subsection{Strategy 5-Integrate Technology into Nursing Education}

Having the appropriate technology infrastructure and upto-date resources is also critical to successful learning. With the impetus to expand the use of technology, lecturers must be prepared to use available resources, have access to needed support, and develop competency for using resources and support. E-learning should be encouraged to thrive, although there are many things to consider in E-learning as far as the level of development is concerned. Issues like accessibility; affordability and feasibility in the face of epileptic power supply raise concerns.

\subsection{Strategy 6-Funding of Nursing Education}

Funding of nursing education is one of the foremost issues. Within the context of this reform, efforts shall be made to ensure appreciable financial allocation to nursing programmes. Against this background the adverse effects which inadequate supply of equipment have on nursing students at all levels can only be imagined. Most students only see and read about certain common equipment in textbooks. Even these textbooks are in the reference sections of the libraries! Some are as old as Methuselah while some are not available for purchase.

\subsection{Strategy 7-Changing the Nomenclature to Reflect Different Levels of Preparation and Role}

The public is confused on who we are and what it means to be a nurse. Nursing is not clear on what the appropriate education for entry to practice is, and how to recognize and reward individual who have achieved a higher 
educational level. Today in Nigeria nurses continue to graduate from Diploma, Bachelor of Nursing Science. The distinction between the nurses who have the different level of preparation is virtually nonexistent. It is high time nurses globally to look at changing the nomenclature in the profession to reflect different levels of preparation and different role expectation. Should we all be registered nurses? I do not think so, perhaps the classification of [8] the novice, advanced beginner, competent proficient and the expert nurse may be use. The major difference will be the range of experience and level of education. The premise is that the baccalaureate graduate is viewed as possessing a liberal education as well as knowledge and skills in nursing. This background enables the graduate to deliver care to individuals, families, groups, and communities with multiple and complex needs in a range of settings. Practice at the technical level focuses more on the individual client with common, well-defined health problems. In the health care setting, these differences in practice are not readily apparent, as nurses, regardless of educational preparation, have similar roles and responsibilities

\subsection{Strategy 8-Continuing Professional Development}

This is an area of challenge for Nigerian nurses in clinical practice. Impressively, many nurses strive to attend as many workshops and seminars as possible for self improvement. An issue that is very often over looked is whether individual nurses are interested in lifelong education for the joy of it, or whether they participate in continuing education programmes for the purpose of job elevation or an opportunity to be away from work. Research is needed in this area. Another issue is the impact of such education on practice. Continuing education has argued by [7] is more than the acquisition of knowledge and that its aim is to change the nursing practice. Despite this assertion there is paucity of research regarding the effects of the continuing professional development on the subsequent clinical practice of participants. This is an anomaly in a climate of where accountability and quality assurance have assumed greater prominence. It is therefore essential to undertake research in the clinical setting that would examine the observable effect of continuing education programmes on clinical practice. This seems to be inevitable given the move towards evidence-based practice in nursing.

\section{CONCLUSION}

It is beyond reasonable doubt that the re envisioning nursing education and practice is about excellent nursing care to clients and the need to examine how the next generation of nurses are being prepared to function effec- tively in a variety of roles throughout a lifetime career. The mandate here is to re-conceptualize nursing education. Rather than focusing on adding, changing and updating content, nurse educators must identify a framework for continuous lifelong learning that includes basic education, academic progression, and continuing clinical competencies. They must also focus on expanding their evidence-based pedagogical repertoire and rethink the teaching and learning process. To accomplish this, nurse educators in partnership with nursing service must enact substantive innovation in schools, document the effects of the innovation being undertaken, and develop the science of nursing education upon which all educators can draw. The ultimate outcome of these efforts is evidencebased approaches to nursing education in which students learn to provide skillful and compassionate nursing care in fluid and uncertain health care.

\section{REFERENCES}

[1] Adelowo, O.E. (1989) The nursing profession in Nigeria. Lantern Books Ltd., Lagos.

[2] Ojo, A.O. (2010) The challenges of best practices and standards in nursing in Nigeria Inaugural lecture series. 4th Edition, Igbenedion University, Okada.

[3] Ugochukwu, C.G. (2004) Improving patient care: A concern for all. Keynoter address at opening ceremony of the International Nurses Week, University of Nigeria Teaching Hospital, Enugu.

[4] Oblinger, D. G. and Oblinger, J.L. (2005) Educating the Net Generation. www.educause.edu/educatingthenetgen.

[5] Diekelmann, N. (2002) “Too much content...” Epistemologies' grasp and nursing education. Journal of Nursing Education, 41, 469-470.

[6] Porter-O’Grady, T. (2001) Profound change: 21st century nursing. Nursing Outlook, 49, 182-186. doi:10.1067/mno.2001.112789

[7] Quinn, F.M. (2000) Principles and practice of nurse education. 4th Edition, Stanley Thornes (Publishers) Ltd., Cheltenham.

[8] Benner, P.E. (1984) From novice to expert: Excellence and power in clinical nursing practice. Addison-Wesley Pub. Co., Menlo Park.

[9] Porter-O’Grady, T. (2003) A different age for leadership. Journal of Nursing Administration, 33, 105-110.

[10] Diekelmann, N. and Ironside, P. (2002) Developing a science of nursing education: Innovation with research. Journal of Nursing Education, 41, 379-380.

[11] Hasse, P.T. (1990) The origins and rise of associate degree nursing education. Duke University Press, Durham.

[12] Oesterle, M. and O’Callaghan, D. (1996) The changing health care environment: Impact on curriculum and faculty. Nursing \& Health Care: Perspectives on Community, 17, 78-81. 